\title{
The Sydney Multicentre Study of Parkinson's disease: a randomised, prospective five year study comparing low dose bromocriptine with low dose levodopa-carbidopa
}

\author{
Mariese A Hely, John G L Morris, Wayne G J Reid, Dudley J O'Sullivan, \\ Peter M Williamson, David Rail, Gerald A Broe, Simon Margrie
}

\begin{abstract}
149 previously untreated patients with Parkinson's disease were recruited over a three year period and randomly allocated to either low dose levodopa-carbidopa ( $\leqslant 600 / 150$ mg/day) or low dose bromocriptine ( $\leqslant 30 \mathrm{mg} / \mathrm{day}$ ). A five year follow up is reported on the 126 patients who completed the dose titration and who have not developed features of atypical Parkinsonism. Levodopa-carbidopa in low dosage adequately controlled symptoms in most patients and delayed the appearance of dyskinesia and end of dose failure for about two years longer than conventional doses. Only a few patients could be managed for more than one year on low dose bromocriptine alone; these patients had mild disease and asymmetric signs. Patients randomised to bromocriptine did not develop dyskinesia or troublesome end of dose failure until levodopa-carbidopa was added. The prevalence of dyskinesia in this group was lower than in patients given levodopa-carbidopa alone. The prevalence of end of dose failure was similar in the two randomisation groups once levodopa was introduced.
\end{abstract}

$(\mathcal{F}$ Neurol Neurosurg Psychiatry 1994;57:903-910)

The Sydney Multicentre Study of Parkinson's disease began in August 1984. Our aim was to compare the efficacy and side effects of low dose levodopa-carbidopa ( $\leqslant 600 / 150 \mathrm{mg} /$ day) and low dose bromocriptine ( $\leqslant 30 \mathrm{mg} /$ day) in the treatment of de novo Parkinson's disease. In particular it was hoped to determine whether the incidence of dyskinesia and fluctuations were lower in the bromocriptine group. Interim results on the first three years of the study have been reported. ${ }^{1}$

The place of bromocriptine in the management of Parkinson's disease remains uncertain though it has been used extensively since $1974 .^{2}$ Because it has a longer plasma half life than levodopa, ${ }^{3}$ it was initially given in high doses (>30 mg/day) as a means of controlling "end of dose failure" in patients with advanced disease. ${ }^{4}$ It rarely caused dyskinesia when given as sole treatment to de novo patients, although other side effects, such as psychosis and postural hypotension, limited its value. ${ }^{5-7} \mathrm{~A}$ study by Teychenne and colleagues ${ }^{8}$ found that de novo patients could be satisfactorily managed on low doses of bromocriptine, with minimal side effects.

In 1985, Rinne ${ }^{9}$ reported a low incidence of dyskinesia and fluctuations in de novo patients given low doses of bromocriptine ( $<30 \mathrm{mg} /$ day), to which low doses of levodopa had been added early in the course of treatment. His control group, given levodopa alone, was from a previous study. More recently, it has been proposed that dopamine agonists such as bromocriptine may, by delaying the introduction of levodopa and reducing the subsequent dose of levodopa, have a neuroprotective role in Parkinson's disease. ${ }^{1011}$

Few patients in the present study could be managed on bromocriptine alone for more than a year or two. Many of these patients are now on a combination of levodopa-carbidopa and bromocriptine. We have thus had the opportunity of comparing this group, one that was derived in a similar way to Rinne's group, ${ }^{9}$ with a contemporary levodopa group. By July 1992, all surviving patients had completed five years whereas some had achieved seven to eight years in the study. The data on response to low dose treatment and the frequency of motor side effects during five years of follow up are presented.

\section{Patients and methods}

Recruitment, diagnosis, stratification, randomisation, dose titration, and code breaking have been reported previously. ${ }^{1}$ The study was designed to be double blind in the titration phase. The dose of each drug was gradually increased on a three times a day dosage until the patient reported a satisfactory response. We did not attempt to abolish all symptoms and signs of the disease. Patients have continued to be followed up regardless of whether the treatment code was broken and no matter what changes have been made to their treatment.

One neurologist $(\mathrm{MH})$ performed baseline, end of titration, and yearly assessments with a modified Columbia scale (maximum score $102)^{12}$ on all patients in the study. She also simultaneously rated clinical signs of patients 
with the other four hospital neurologists to improve between rater reliability. ${ }^{13}$ When fluctuations were present, the score when "on" was taken for comparison with baseline.

Absolute change in the Columbia score and its components are compared with baseline values for each group of patients at six months then at yearly intervals. We also grouped patients according to whether their Columbia score changed by five to nine or more than 10 points compared with the baseline. We chose a change of five or more points as significant as this is outside our between rater error range. ${ }^{13}$

Activities of daily living were recorded on a nine item modified North West University disability scale. ${ }^{14}$ Severity of disease was graded on the Hoehn and Yahr scale. ${ }^{15}$ Symptoms and side effects were recorded and graded on standard questionnaires. Severity of dyskinesia was graded on a five point scale. ${ }^{16}$

Analyses were performed on the two monotherapy treatment groups as originally randomised-that is, bromocriptine alone (B) and levodopa-carbidopa alone (LD), on the two groups as randomised even though treatment may have changed, and also on the main treatment subgroups that subsequently formed-for example, bromocriptine to bromocriptine and levodopa-carbidopa combined group ( $\mathbf{B} \rightarrow \mathbf{B}+\mathrm{LD})$ and bromocriptine to levodopa-carbidopa group (B $\rightarrow$ LD). Other subgroups were too small to consider independently and the levodopa-carbidopa to levodopa-carbidopa and bromocriptine treatment group is not considered in the early combination group.

In assessing the prevalence of late side effects, such as dyskinesia or fluctuations at each point in time throughout the trial patients were counted as having the side effects from the time that they occurred, even if they disappeared with adjustment of treatment.

Fluctuation (end of dose failure) was recorded as being present if the patient reported on questioning or was seen by us to have: early morning akinesia of any degree; wearing off of the effect of each dose before the next was due on a three times a day dosage; dosage frequency more than three times daily.

Fluctuations have been graded as mild,

Table 1 Randomisation groups: baseline data

\begin{tabular}{|c|c|c|c|c|}
\hline & \multicolumn{2}{|c|}{ Bromocriptine $(n=62)$} & \multicolumn{2}{|c|}{ Levodopa-carbidopa $(n=64$} \\
\hline & Mean (SD) & No $(\%)$ & Mean (SD) & No (\%) \\
\hline \multicolumn{5}{|l|}{ Items: } \\
\hline Age at entry (y) & $62(9 \cdot 8)$ & & $62(9 \cdot 8)$ & \\
\hline Duration of disease & & & & \\
\hline $\begin{array}{l}\text { before trial (months) } \\
\text { Modified Columbia Score }\end{array}$ & $\begin{array}{l}22(18 \cdot 0) \\
18 \cdot 3(9 \cdot 0)\end{array}$ & & $\begin{array}{l}25(22 \cdot 8) \\
15 \cdot 3(6 \cdot 8)\end{array}$ & \\
\hline Modified North West University & & & & \\
\hline disability score & $4 \cdot 4(3 \cdot 4)$ & & $3 \cdot 3(2 \cdot 2)$ & \\
\hline Hoehn and Yahr score & $2 \cdot 3(0.5)$ & & $2 \cdot 2(0 \cdot 6)$ & \\
\hline \multirow{2}{*}{\multicolumn{5}{|c|}{ Patients: }} \\
\hline & & & & \\
\hline I & & $2(3)$ & & $6(9)$ \\
\hline II & & $38(61)$ & & $37(58)$ \\
\hline III & & $22(35)$ & & $21(33)$ \\
\hline Dementia & & $12(19)$ & & $7(11)$ \\
\hline Gait disorder & & $11(18)$ & & $5(8)$ \\
\hline
\end{tabular}

moderate, or severe (see table 5 for definitions). The term "on-off" is reserved for sudden, severe and at times unpredictable changes in mobility. We attempted to separate involuntary movements into two types: (a) dyskinesia, where the movements were rapid, irregular, and painless; (b) dystonia, where sustained abnormalities of posture, sometimes painful, occurred.

The time of onset of late side effects was taken as the first visit at which the patient reported it or the neurologist identified it (whichever came first).

Statistical analyses to compare treatment subgroups or to assess change from baseline within the subgroups were based on the two sample $t$ test, paired $t$ test, or the Wilcoxon rank sum test. The last test was used if the assumptions required for the $t$ test (mainly normality of the distribution of the variable in question) were not met. Although the Wilcoxon rank sum test is calculated on the medians, means and standard deviations (SDs) are provided in the tables as they tend to give a better indication of the magnitude of change or subgroup differences than the medians. Standard $\chi^{2}$ analyses were used when comparing treatment subgroups with regard to prevalence of categorical patient characteristics - for example, presence of late side effects or not, or categorical variables such as Hoehn and Yahr stages. The duration on either drug as monotherapy was treated as a survival time and log rank and Peto statistics ${ }^{17}$ were used to test for a difference between the survival curves.

\section{Results}

One hundred and forty nine patients aged from 37 to 79 years were recruited over a three year period from 1984 to 1987 .

\section{EXCLUSIONS}

Ten patients were excluded after the initial assessment period as it was considered that their Parkinsonism was atypical. ${ }^{1}$ As the study progressed, three further patients were excluded: two with features of multisystem atrophy and one with progressive supranuclear palsy. Ten patients failed to complete the dose titration phase. ${ }^{1}$

\section{PATIENT COHORTS}

One hundred and twenty six patients remained who did not show atypical features and who had completed the titration phase. There were 70 men and 56 women. Of these, 62 were randomised to bromocriptine and 64 to levodopa-carbidopa. There were no statistically significant differences between the groups (table 1). More patients with dementia and gait disorder were randomised to receive bromocriptine, however. Table 2 shows the numbers of patients in each treatment group progressing through the study. Few patients could be managed on bromocriptine alone after two years. The median time on bromocriptine as monotherapy was $12 \cdot 1$ months (95\% CI 8.5-17.7 months) whereas 
Table 2 Patient cohorts at each year of study

\begin{tabular}{|c|c|c|c|c|c|}
\hline & \multicolumn{5}{|c|}{ Time $(y)$} \\
\hline & 1 & 2 & 3 & 4 & 5 \\
\hline \multicolumn{6}{|c|}{ Group randomised to bromocriptine } \\
\hline B alone & 32 & 18 & 5 & 1 & 0 \\
\hline$B \rightarrow B+L D$ & 9 & 11 & 16 & 18 & 18 \\
\hline $\mathrm{B} \rightarrow \mathrm{LD}$ & 11 & 16 & 17 & 15 & 12 \\
\hline $\mathrm{B} \rightarrow \mathrm{B}+\mathrm{A}$ & 1 & 3 & 2 & 2 & 2 \\
\hline B $\rightarrow$ VAR & 1 & 3 & 7 & 8 & 10 \\
\hline Not seen & 2 & 7 & 10 & 11 & 8 \\
\hline Off drugs & 6 & 3 & 3 & 3 & 3 \\
\hline Dead & 0 & 1 & 2 & 4 & 9 \\
\hline Total & 62 & 62 & 62 & 62 & 62 \\
\hline \multicolumn{6}{|c|}{ Group randomised to levodopa-carbidopa } \\
\hline LD alone & 56 & 51 & 42 & 38 & 31 \\
\hline $\mathrm{LD} \rightarrow \mathrm{LD}+\mathrm{A}$ & 2 & 3 & 5 & 5 & 5 \\
\hline $\mathrm{LD} \rightarrow \overline{\mathrm{LD}}+\mathrm{B}$ & 3 & 6 & 9 & 7 & 11 \\
\hline $\mathrm{LD} \rightarrow \overline{\mathrm{B}}$ & 1 & 0 & 0 & 0 & 0 \\
\hline $\mathrm{LD} \rightarrow$ VAR & 0 & 1 & 1 & 2 & 6 \\
\hline Not seen & 2 & 3 & 4 & 8 & 4 \\
\hline Off drugs & 0 & 0 & 2 & 1 & 0 \\
\hline Dead & 0 & 0 & 1 & 3 & 7 \\
\hline Total & 64 & 64 & 64 & 64 & 64 \\
\hline
\end{tabular}

the median time on levodopa-carbidopa alone was 52.3 months $(95 \%$ CI $46 \cdot 6-\ldots)$. No patient was able to remain on bromocriptine alone for five years. Anticholinergic drugs were added to the regimen of 15 patients with severe tremor (eight in the bromocriptine group and seven in the levodopa-carbidopa group).

\section{REASONS FOR CODE BREAKING \\ Bromocriptine group}

Lack of efficacy was the main reason for patients failing to remain on bromocriptine alone. This was despite the fact that the low dose limit of $30 \mathrm{mg} /$ day was eventually exceeded in many cases. The mean dose of bromocriptine was $32 \mathrm{mg}$ /day (range 7.5-60 $\mathrm{mg} /$ day). Levodopa-carbidopa was added to bromocriptine in most of these cases to form the "bromocriptine to combination treatment" (B $\rightarrow$ B + LD) group.

Other reasons for withdrawing bromocriptine included confusion and hallucinations (10 patients); postural hypotension (four patients), and nausea (four patients). These side effects generally occurred within the first year of treatment. Levodopa-carbidopa was substituted for bromocriptine in these patients, forming the bromocriptine to levodopa-carbidopa (B $\rightarrow$ LD) group.

Seven of 10 patients who became confused on bromocriptine also became confused on low dose levodopa-carbidopa. Of these 10 patients, seven satisfied criteria for dementia. ${ }^{18}$

\section{Levodopa-carbidopa group}

The main reasons for breaking the code in the levodopa-carbidopa group were dyskinesia and dystonia (see later). Low dose levodopacarbidopa proved ineffective in eight patients who had rapidly progressive disease (mean dose $475 \mathrm{mg} /$ day, range 300-600 mg/day); a further six patients experienced confusion and hallucinations and four patients on levodopacarbidopa had nausea.

SERIOUS SIDE EFFECTS

One patient developed retroperitoneal fibrosis
Table 3 Dose (mg/day) of levodopa and bromocriptine for each group

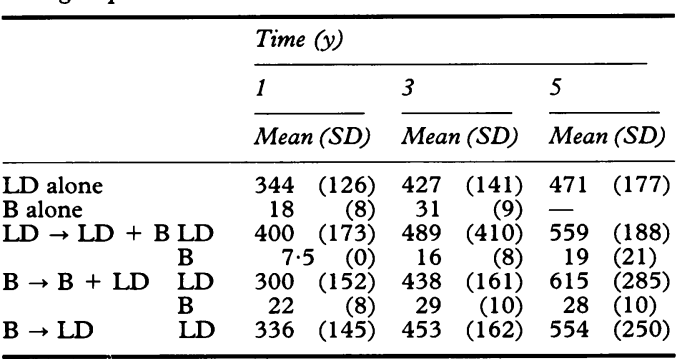

after three years of bromocriptine (maximum dose $30 \mathrm{mg} /$ day). ${ }^{19}$ Two patients developed pulmonary fibrosis after 2.5 and five years of bromocriptine (maximum dose $30 \mathrm{mg} /$ day). All patients recovered after stopping bromocriptine although the patient with retroperitoneal fibrosis required surgical intervention.

RESPONSE TO TREATMENT

Table 3 shows the mean doses used for each drug at one and five years. Although increasing gradually with time, they remained lower than conventional doses. The $\mathrm{B} \rightarrow \mathrm{LD}$ and B $\rightarrow$ B + LD groups both had higher doses of levodopa-carbidopa than the group that remained on levodopa-carbidopa alone; however, the difference was not significant even at five years (Kruskal Wallis test, $p=0 \cdot 165$ ).

Figure 1 shows the change in Columbia score compared with baseline from six months to five years for patients who remained on bromocriptine and levodopa-carbidopa alone and also for patients who were in the $B \rightarrow L D$ and $\mathrm{B} \rightarrow \mathrm{B}+\mathrm{LD}$ groups. The levodopa-carbidopa group was significantly better than baseline for two years $(p<0.001)$ and remained better than baseline for four years whereas the few patients who remained on bromocriptine alone were better than baseline for only one year and were significantly worse by two years $(p=0.004)$. Patients in the $B \rightarrow$ $B+$ LD group remained better than baseline at five years but the numbers of patients in this group were small and the results did not achieve significance. Patients in the $B \rightarrow L D$ group deteriorated more rapidly reaching baseline scores at about three years, although their initial response to levodopa was good.

The actual numbers of patients who improved or deteriorated shows a similar trend for each treatment group to that above, which reflects the mean change (table 4). Levodopa-carbidopa alone was significantly better than bromocriptine alone at one year $(p$ $=0.009)$ and $B \rightarrow B+L D$ was significantly better than levodopa-carbidopa alone $(\mathrm{p}=$ 0.002 ). At five years more patients in the $B \rightarrow$ B + LD group were improved compared with the baseline and fewer had deteriorated than in the levodopa-carbidopa alone group $(p=$ 0.047 ).

In interpreting the outcome of patients originally allocated bromocriptine, it is important to recognise that selection processes determined the new treatment subgroups that formed. Patients in the $B \rightarrow L D$ group had more severe disease and were older at entry 
Figure 1 Mean change in modified Columbia score for the patient groups over five years expressed as the score for each patient compared with his or her score at baseline (patients on anticholinergic drugs excluded).

\begin{tabular}{|c|c|c|c|c|c|c|}
\hline \multirow[b]{2}{*}{ Group } & \multicolumn{6}{|l|}{$\operatorname{Time}(y)$} \\
\hline & 0.5 & 1 & 2 & 3 & 4 & 5 \\
\hline $\begin{array}{l}\mathrm{B} \\
\mathrm{LD} \\
\mathrm{B} \rightarrow \mathrm{B}+\mathrm{LD} \\
\mathrm{B} \rightarrow \mathrm{LD}\end{array}$ & $\begin{array}{l}-2 \cdot 41^{\star \star} \\
(0 \cdot 67) \\
-3 \cdot 69^{\star \star \star} \\
(0 \cdot 72) \\
- \\
-\end{array}$ & $\begin{array}{l}-0.42 \\
(0.80) \\
-3.96^{\star \star \star} \\
(0.74) \\
-5.75 \\
(3.08) \\
-5.44^{\star} \\
(1.86)\end{array}$ & $\begin{array}{l}+3 \cdot 47^{\star \star} \\
(1 \cdot 04) \\
-3 \cdot 19 \star \star \star \\
(0 \cdot 87) \\
-5 \cdot 36 \\
(2 \cdot 60) \\
-2 \cdot 64 \\
(2 \cdot 51)\end{array}$ & $\begin{array}{l}+5.20 \\
(3 \cdot 22) \\
-1 \cdot 67 \\
(1.06) \\
-3.81 \\
(1 \cdot 80) \\
+0.27 \\
(1.66)\end{array}$ & $\begin{array}{l}+4 \cdot 0 \\
(-) \\
+0 \cdot 10 \\
(1 \cdot 28) \\
-1 \cdot 44 \\
(2 \cdot 27) \\
+5 \cdot 86^{\star} \\
(2 \cdot 41)\end{array}$ & $\begin{array}{l}- \\
+2.31 \\
(1.80) \\
-1.94 \\
(1.92) \\
+9.73^{\star} \\
(3.18)\end{array}$ \\
\hline
\end{tabular}

${ }_{\star \star \star \star} \mathrm{p}<0.05 ;{ }^{\star \star} \mathrm{p}<0.01$

Values are means (SEM)

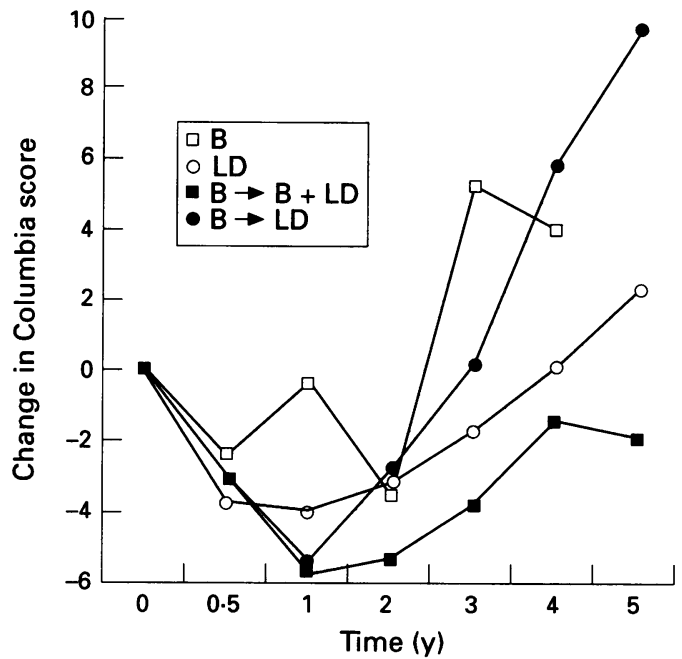

Table 4 Number of patients improved or deteriorated in modified Columbia score at one and five years compared with baseline

\begin{tabular}{lllrrr}
\hline & $\begin{array}{l}\text { Improved } \\
(>9 \text { points) }\end{array}$ & $\begin{array}{l}\text { Improved } \\
(5-9 \text { points) }\end{array}$ & $\begin{array}{l}\text { Stable } \\
( \pm 4 \text { points) }\end{array}$ & $\begin{array}{l}\text { deteriorated } \\
(>4 \text { points) }\end{array}$ & $\begin{array}{c}\text { total } \\
\text { No }\end{array}$ \\
\hline 1 year: & & & & & \\
B alone & $1(3 \cdot 1)$ & $4(12 \cdot 5)$ & $24(75 \cdot 0)$ & $3(9 \cdot 4)$ & 32 \\
B $\rightarrow$ B + LD & $5(55 \cdot 6)$ & $1(11 \cdot 1)$ & $2(22 \cdot 2)$ & $1(11 \cdot 1)$ & 9 \\
B $\rightarrow$ LD & $2(18 \cdot 2)$ & $2(18 \cdot 2)$ & $6(54 \cdot 5)$ & $1(9 \cdot 1)$ & 11 \\
LD alone & $6(10 \cdot 7)$ & $18(32 \cdot 1)$ & $31(55 \cdot 4)$ & $1(1 \cdot 8)$ & 56 \\
$\begin{array}{l}\text { years: } \\
\text { B } \rightarrow \text { B + LD }\end{array}$ & $5(27 \cdot 8)$ & 0 & $10(55 \cdot 6)$ & $3(16 \cdot 7)$ & 18 \\
B $\rightarrow$ LD & 0 & $1(8 \cdot 3)$ & $3(25 \cdot 0)$ & $8(66 \cdot 7)$ & 12 \\
LD alone & $2(6 \cdot 5)$ & $5(16 \cdot 1)$ & $13(41 \cdot 9)$ & $11(35 \cdot 5)$ & 31 \\
\hline
\end{tabular}

Numbers in parentheses are percentages.

Figure 2 Mean change in modified North West University disability score (NWUDS) for the patient groups over five years expressed as the score for each patient compared with his or her score at baseline (patients on anticholinergic drugs excluded).

\begin{tabular}{|c|c|c|c|c|c|c|}
\hline \multirow[b]{2}{*}{ Group } & \multicolumn{6}{|l|}{$\operatorname{Time}(y)$} \\
\hline & 0.5 & 1 & 2 & 3 & 4 & 5 \\
\hline B & $\begin{array}{l}-0.26 \\
(0.21)\end{array}$ & $\begin{array}{l}+0.09 \\
(0.28)\end{array}$ & $\begin{array}{l}+1.65^{\star \star} \\
(0.54)\end{array}$ & $\begin{array}{l}+1.20 \\
(0.80)\end{array}$ & +2.00 & - \\
\hline $\mathrm{LD}$ & $-0.40^{\star}$ & $-0 \cdot 75^{\star}$ & $\begin{array}{l}+0.10 \\
+\end{array}$ & +0.34 & $+1 \cdot 39 \star \star$ & 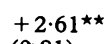 \\
\hline $\mathrm{B} \rightarrow \mathrm{B}+\mathrm{LD}$ & $\underline{(0 \cdot 20)}$ & $\begin{array}{l}(0.26) \\
-0.67\end{array}$ & $\begin{array}{l}(0.38) \\
-0.75\end{array}$ & $\begin{array}{l}(0.37) \\
+0.50\end{array}$ & $\begin{array}{l}(0.61) \\
+0.94\end{array}$ & $\begin{array}{l}(0.81) \\
+1.78\end{array}$ \\
\hline 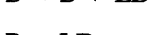 & & $(1 \cdot 38)$ & $(1 \cdot 19)$ & $(0 \cdot 89)$ & $(0 \cdot 88)$ & $(0.83)$ \\
\hline B $\rightarrow$ LD & 一 & $\begin{array}{l}-0.55 \\
(0.82)\end{array}$ & $\begin{array}{l}+2.00 \\
(0.90)\end{array}$ & $\begin{array}{l}+2.61 \text { } \\
(0.77)\end{array}$ & $\begin{array}{l}+5 \cdot 81^{\star \star} \\
(1.35)\end{array}$ & $\begin{array}{l}+6.64^{\star \star} \\
(1.47)\end{array}$ \\
\hline
\end{tabular}

$\star \star * p<0.01$

Results are means (SD).

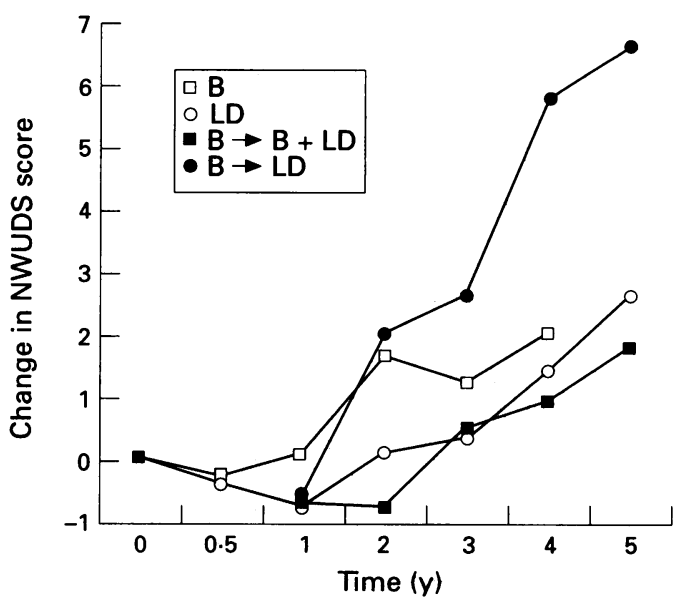

$(65.5 v 59.5$ years) than the $\mathrm{B} \rightarrow \mathrm{B}+\mathrm{LD}$ group. At baseline, $B \rightarrow$ LD patients had more dementia $\left(8 / 26 v 1 / 21, \chi^{2}=5.08\right.$, $\mathrm{p}<0.05)$, more gait and balance disorders $(6 / 26 v 2 / 21, \mathrm{NS})$, slightly higher Columbia scores $(19.8 v 18.9)$, and more advanced Hoehn and Yahr stage $(2.5 v 2 \cdot 2)$. This may explain the poor progress made by the $B \rightarrow L D$ group during the course of the trial. The B $\rightarrow$ B + LD group, though less severely affected than the $B \rightarrow$ LD group, had slightly higher mean Columbia and North West University disability scores than the levodopacarbidopa monotherapy group at baseline.

Patients on bromocriptine alone showed improvement in rigidity $(p<0.01)$ and bradykinesia $(p<0.05)$ at six months but not thereafter. Tremor was not significantly improved. Patients on levodopa-carbidopa alone showed significant improvement in rigidity, bradykinesia, and tremor compared with baseline for up to two years.

Changes in modified North West University Disability score over the five years followed a similar pattern to changes in modified Columbia score for each of the groups (fig 2).

The 13 patients who were able to remain on bromocriptine alone without deterioration for two years had a higher incidence of asymmetric disease $(77 \%$ compared with $36 \%$ of those who had already failed on bromocriptine monotherapy, $\chi^{2}=6.70, p<0.01$ ) and a higher incidence of tremor with bradykinesia/rigidity ( $85 \%$ compared with $51 \%, \chi^{2}=$ $4.76, \mathrm{p}<0.05)$. Their age range at entry was wide (49 to 72 years), with a mean of 64 years. Their mean Columbia score was 16 whereas that of patients who had failed on bromocriptine was 20 .

\section{DYSKINESIA}

Fifty two patients had developed dyskinesia by five years. Thirty five were from the patients randomised to levodopa-carbidopa and 17 from the group randomised to bromocriptine but later given levodopa-carbidopa as well as bromocriptine, ${ }^{10}$ instead of bromocriptine, ${ }^{6}$ or in a variable manner. ${ }^{1}$ The difference between the groups as randomised is significant at five years $(p=0.002)$. No patients developed dyskinesia while on bromocriptine alone.

Figure 3 shows the time to dyskinesia from the onset of treatment according to randomisation group. There was no significant difference between the $B \rightarrow L D$ and $B \rightarrow B+L D$ subgroups. Incidence for newly diagnosed dyskinesia was estimated for each six month period over the five years of the study. The average incidence of newly arising dyskinesia was $\mathbf{7 \cdot 4 \%}$ for each six months of treatment with levodopa-carbidopa. For patients currently receiving levodopa-carbidopa the six monthly incidence for dyskinesia was higher for patients who had been treated longer with levodopa-carbidopa $\left(\chi^{2}=19, \mathrm{p}<0.0001\right)$.

The incidence was higher for women than for men $\left(\chi^{2}=4.0, p=0.05\right)$ for younger than for older patients $\left(\chi^{2}=4 \cdot 2, p=0.04\right)$ and for patients with more severe initial disease as measured by modified Columbia score $\left(\chi^{2}=\right.$ 
Figure 3 Kaplan-Meier plot showing the time to dyskinesia according to randomised treatment groups. The five patients who did not receive levodopa-carbidopa are excluded.

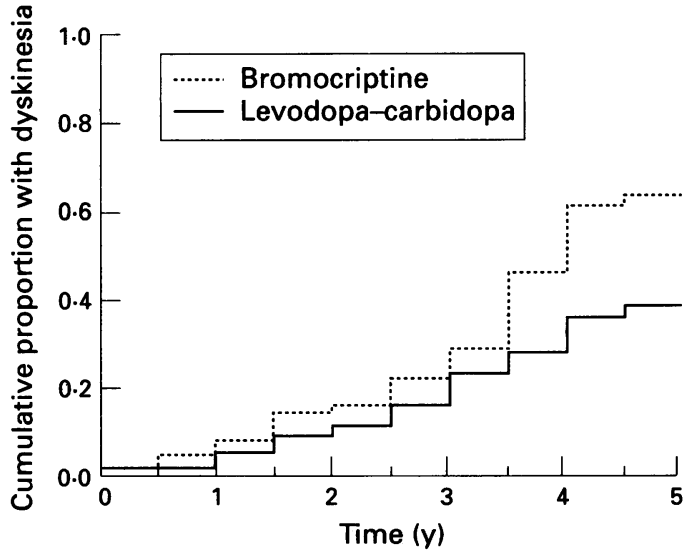

$4 \cdot 3, \mathrm{p}=0.04)$. It did not vary greatly with pretreatment disease duration $\left(\chi^{2}=0.6\right.$, $p>0.05$ ). After taking account of duration of treatment with levodopa-carbidopa, sex, age, and initial severity of disease, the incidence was higher for patients currently being treated with higher doses of levodopa-carbidopa $\left(\chi^{2}=4 \cdot 6, p=0 \cdot 03\right)$. Taking account of all these variables, however, the incidence did not differ with randomisation group $\left(\chi^{2}=0 \cdot 0\right.$, $\mathrm{p}=1 \cdot 0$ ) once levodopa was commenced. In patients continuing on bromocriptine with the addition of levodopa-carbidopa, the incidence rate did not vary with bromocriptine dose $\left(\chi^{2}=0 \cdot 0, \mathrm{p}=1 \cdot 0\right)$.

After five years, the prevalence of dyskinesia approached that found with conventional doses. The severity of the dyskinesia, however, remained mild with $71 \%$ of the levodopa-carbidopa group and $76 \%$ of the bromocriptine group graded as 1 on the Unified Parkinson's Disease Rating Scale. ${ }^{16}$ Only one patient was grade 3 and no patients were grade 4 or 5 .

The period of treatment with levodopa-carbidopa in patients who did not develop dyskinesia was longer than the time to dyskinesia in those with dyskinesia (mean for all patients without dyskinesia $46 v 35$ months, median $54 v 36$ months ( $\mathrm{p}=0.003)$; mean for levodopa randomised patients without dyskinesia 55 months and for bromocriptine randomised patients without dyskinesia 41 months). Their dose of levodopa-carbidopa was slightly higher, when last seen, than that at the time of onset of dyskinesia in those with dyskinesia

Figure 4 Kaplan-Meier plot showing time to end of dose failure according to randomised treatment groups. The five patients who did not receive levodopa-carbidopa are excluded.

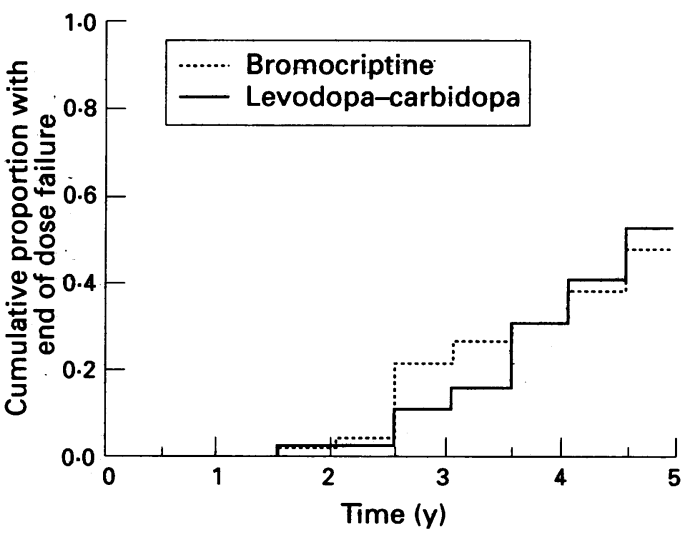

(mean for all patients without dyskinesia $\mathbf{5 2 5}$ $\mathrm{mg} /$ day $v 499 \mathrm{mg} /$ day, NS). Thus the dose of levodopa-carbidopa and the follow up were adequate in patients who did not develop dyskinesia compared with those who did.

\section{END OF DOSE FAILURE}

Twenty three out of $62(37 \%)$ patients from the bromocriptine randomised group (20/27 after addition of levodopa-carbidopa) and 26 out of $64(41 \%)$ patients from the levodopacarbidopa group developed end of dose failure by five years. Figure 4 shows the time to end of dose failure in each randomisation group. In 42 out of $49(86 \%)$, the end of dose failure was graded as mild (table 5). Only one patient developed the on-off phenomenon.

Incidence for newly diagnosed end of dose fluctuations was estimated for each six month period over five years of the study. No end of dose fluctuations were detected in the first year of the study. The incidence increased over time, reaching $18 \%$ in the last six months. Although the time in the study and duration of levodopa-carbidopa use are highly correlated, it seems that the variation in incidence of end of dose fluctuations is largely explained by the time in the study. The variation with time in the study is statistically significant $\left(\chi^{2}=37 \cdot 0, p<0.001\right)$, with duration of levodopa-carbidopa treatment providing little more additional explanation $\left(\chi^{2}=0.4\right.$, $\mathrm{p}>0.05)$.

Higher doses of levodopa-carbidopa were associated with a higher incidence of end of dose fluctuations $\left(\chi^{2}=7 \cdot 7, \mathrm{p}<0.01\right)$. Sex, age, initial Columbia score, and pretreatment duration of disease explain little of the variation in the incidence of end of dose fluctuations $\left(\chi^{2}=3.3, \quad p>0.05\right)$. After taking account of these variables incidence did not differ with randomisation group $\left(\chi^{2}=0 \cdot 0\right.$, $\mathrm{p}>0.05$ ).

Patients who had not developed end of dose failure had been treated longer with levodopa-carbidopa (mean $50 \quad v \quad 40$ months, median $54 v 36$ months, $\mathrm{p}<0.01$ ) than patients who had developed end of dose failure; thus lack of follow up is not a factor in explaining the absence of end of dose failure.

\section{DYSTONIA}

Dystonia mainly involved abnormal posturing of the feet and toes in the early morning. There were 31 patients with foot dystonia: 10 randomised to bromocriptine, of whom nine had received levodopa-carbidopa before the dystonia developed and 21 randomised to levodopa-carbidopa $\left(\chi^{2}=4.7, p<0.05\right)$. Two other patients in the levodopa-carbidopa group developed painful dystonia in the upper and lower limbs of the most affected side (a total of 23 levodopa-carbidopa patients). Four patients (two originally randomised to levodopa-carbidopa, two to bromocriptine) with foot dystonia later developed more proximal upper and lower limb dystonia while on levodopa-carbidopa. Overall, dystonia was significantly more of a problem in patients randomised to levodopa-carbidopa (mean 
Table 5 Severity of end of dose failure after five years

\begin{tabular}{lllll}
\hline Group & Mild & Moderate & Severe & Total \\
\hline LD \& LD $\rightarrow$ LD + B & 21 & 3 & $2 \star$ & 26 \\
B $\rightarrow$ B + LD, B $\rightarrow$ LD, B $\rightarrow$ VAR & 21 & 1 & 1 & 23 \\
Total & 42 & 4 & 3 & 49 \\
\hline
\end{tabular}

${ }^{\star}$ One patient with on-off phenomenon: Mild = Early morning akinesia \pm dosage frequency $3-4 /$ day; moderate $=$ duration of effect of each dose $>3$ hours + dosage frequency $4-5 /$ day; severe $=$ duration of effect of each dose $\leqslant 3$ hours \pm dosage frequency $>5 /$ day, fluctuations interfere with lifestyle. year, in this study, was $18 \mathrm{mg} /$ day. Although the dose was individually titrated for each patient, the rate of dosage increment was calculated on the basis that $1 \mathrm{mg}$ of bromocriptine is equivalent to $20 \mathrm{mg}$ of levodopa (plus decarboxylase inhibitor). Bromocriptine has fared better in comparison with levodopa in studies where a ratio of $1: 10$ of bromocriptine to levodopa was used..$^{22-24}$ In de novo patients, the best results for bromocriptine, used alone, have been achieved when more than 30 $\mathrm{mg} /$ day is given, half to two thirds of patients being at least $25 \%$ improved at one year. ${ }^{525}$ Even at these higher doses, however, few patients can be sustained on bromocriptine alone in the long term. On average $15 \%$ reach four to five years 569226 and nearly half of these also receive anticholinergics or amantadine.

In this study, lack of efficacy rather than side effects was the main reason that bromocriptine monotherapy failed. We found that doses below $15 \mathrm{mg} /$ day rarely produced sustained benefit. The patients who best tolerated bromocriptine monotherapy had mild disease, asymmetric signs, and were not demented. Other studies ${ }^{626}$ have also found that bromocriptine is best tolerated by patients with mild, early disease.

It is not known why bromocriptine, as the sole treatment, is only effective early in the course of Parkinson's disease. Its main action is thought to be as an agonist for striatal $\mathrm{D}_{2}$ dopamine receptors; perhaps some $D_{1}$ excitation is necessary to achieve the maximal effect. ${ }^{27} 28$ Early in the disease, this could be provided by endogenous dopamine released from surviving nigrostriatal neurons. Some of its effect may also depend on stimulation of $\mathrm{D}_{2}$ autoreceptors on nigrostriatal neurons. ${ }^{29}$ Progressive loss of striatonigral neurons with progression of the disease would then reduce its efficacy.

\section{Early combination therapy}

All the patients who continued through the study who were originally randomised to bromocriptine were eventually switched to levodopa-carbidopa or a combination of the two drugs. The more mildly affected patients in this group went on to combination treatment; their disability was, nevertheless, more pronounced than that of the patients randomised to levodopa. Despite this, the B $\rightarrow$ B + LD group at times during the course of the trial, showed significantly more improvement in the modified Columbia score than did the levodopa-carbidopa group, suggesting a possible potentiating effect of bromocriptine on levodopa-carbidopa. The more severely affected $B \rightarrow$ LD group had evidence of aspects of Parkinson's disease, such as gait disorder and dementia, which are less responsive to levodopa. They seemed to have a more rapidly progressive form of disease, which was difficult to manage.

\section{LATE SIDE EFFECTS}

No patient treated with bromocriptine alone developed dyskinesia, or the on-off phenome- 
non. One patient developed early morning foot dystonia and three developed mild end of dose failure while on bromocriptine alone.

Giving levodopa-carbidopa in low dosage did not prevent the appearance of dyskinesia and end of dose failure but the incidence of these long term problems was reduced, particularly in the first three years. ${ }^{1}$ The median time to the appearance of these late side effects has been delayed by about two years by low doses of levodopa-carbidopa. When higher doses of levodopa were used in previous studies, ${ }^{30-32} 50 \%$ to $90 \%$ of patients had dyskinesia in the first three years. End of dose failure was reported as $2 \%$ to $13 \%$ at one to three years. ${ }^{24}$ 32-34

By five years the cumulative percentage of patients in the levodopa-carbidopa group who reported dyskinesia at any stage approached the $47 \%$ to $73 \%$ quoted for conventional doses. $^{9213033}$ It should be noted that our patients are counted as having dyskinesia once dyskinesia appears even if it then goes with adjustment of medication. Some studies report a decrease in the prevalence of dyskinesia with time, after a reduction in the dosage of levodopa. ${ }^{21} 303134$ The severity of dyskinesia in our patients was mild and rarely dose limiting.

The number of patients counted as having end of dose failure, even if no longer present as a result of more frequent dosing, also approached the $50 \%$ to $70 \%$ reported in patients on conventional doses after four to six years. ${ }^{92134}$ Again, we believe that the severity of this late side effect is milder than with higher doses, in part due to the smaller dose of levodopa producing less noticeable improvement. Only $1 \%$ of patients developed the on-off phenomenon compared with the expected $10 \% .^{2131}$ It seems likely that giving levodopa-carbidopa in low dosage keeps more patients below their thresholds for end of dose failure or dyskinesia. Whether or not there is an added benefit from keeping levodopa dosage low and thereby reducing its possible harmful effects is uncertain.

The early use of bromocriptine significantly reduced the prevalence of dyskinesia at five years after levodopa-carbidopa was added in the group originally randomised to bromocriptine when compared with the group randomised to levodopa-carbidopa. This was not due to a dose sparing effect on levodopacarbidopa once it was started nor to a lack of adequate follow up but may have been related to the delay in the introduction of levodopacarbidopa. The pattern of recruitment from multiple neurologists and the clinical characteristics of the patients did not change much over the three year period of recruitment.

We found no evidence to support the idea that bromocriptine delays the progression of the disease although few patients stayed on this drug alone for more than a year. The number of deaths was equal in the two randomisation groups. The incidence of end of dose failure was not reduced by the early use of bromocriptine. It is too early to judge whether bromocriptine reduces the incidence of on-off phenomena in those patients who continue to be followed up.

In conclusion:

(1) levodopa-carbidopa in low dosage produced an acceptable level of control of symptoms in most patients and delayed the appearance of dyskinesia and end of dose failure by about two years compared with conventional doses. When these late side effects occurred, they were milder than usual.

(2) Low dose bromocriptine monotherapy did not cause dyskinesia and only rarely caused mild end of dose failure but was less effective than low dose levodopa-carbidopa. Only a few patients could be managed on it alone for more than one year.

(3) There was a reduction in the prevalence of levodopa induced dyskinesia in the patients started on bromocriptine to which levodopacarbidopa was later added. This benefit was sustained over a five year period and could not be explained by a levodopa sparing effect once levodopa was started.

(4) Bromocriptine should be avoided in patients with dementia. Patients receiving long term bromocriptine should have regular auscultation and occasional chest radiographs to look for evidence of pleural fibrosis. Changes in bowel or bladder habits or the occurrence of deep vein thrombosis should alert the clinician to the possibility of retroperitoneal fibrosis.

(5) We recommend that patients be treated according to their needs and that the introduction of levodopa should not be delayed once the patient has disability sufficient to interfere with everyday activities. Whenever possible, levodopa should be given in low dosage to minimise late side effects. Bromocriptine monotherapy may be tried in the early stage of the disease in patients with asymmetric signs and mild disability. The early use of bromocriptine seems to be associated with a reduced incidence of dyskinesia once levodopa is introduced.

This study was funded by a grant from Sandoz (Australia).

1 Hely MA, Morris JGL, Rail D, et al. The Sydney Multicentre Study of Parkinson's disease: a report on the first three years. I Neurol Neurosurg Psychiatry 1989;52 $324-8$.

2 Calne DB, Teychenne PF, Claveria LE, et al. Bromocriptine in Parkinson's disease. BMf 1974;4:442-4.

3 Aellig WH, Nuesch E. Comparative pharmacokinetic investigation with tritium-labelled ergot alkaloids after oral and intravenous administration to man. Int $\mathcal{F}$ Clin Pharmacol 1977;115:106-12.

4 Parkes JD, Debono AG, Marsden CD. Bromocriptine in Parkinsonism: long-term treatment, dose response and comparison with levodopa. $\mathcal{F}$ Neurol Neurosurg Psychiatry 1976;39:1101-8.

5 Stern GM, Lees AJ. Sustained bromocriptine therapy in 50 previously untreated patients with Parkinson's 50 previously untreated patients
disease. Adv Neurol 1983;37:17-21.

6 Bergamasco B, Benna P, Scarzella L. Long-term Bergamasco B, Benna P, Scarzella L. Long-term
bromocriptine treatment of de novo patients with bromocriptine treatment of de novo patients with
Parkinson's disease. A seven-year follow-up. Acta Neurol Parkinson's disease. A
Scand 1990;81:383-7.

7 UK Bromocriptine Research Group. Bromocriptine in Parkinson's disease: a double-blind study comparing 'low-slow' and 'high-fast' introductory dosage regimens in de novo patients. I Neurol Neurosurg Psychiatry 1989;52:77-82.

8 Teychenne PF, Bergsrud D, Racy A, et al. Bromocriptine: low dose therapy in Parkinson's disease. Neurology 1982 32:577-83.

9 Rinne UK. Combined bromocriptine-levodopa therapy early in Parkinson's disease. Neurology 1985;35:1 196-8. 
10 Lieberman A. Dopamine agonists used as monotherapy in de novo PD patients: comparisons with selegiline. Neurology 1992;42(suppl 4):37-40.

11 Olanow CW. Dopamine agonists: a review. In: Lieberman A, Lataste X, eds. Parkinson's disease: the role of dopamine agonists. New Jersey: Parthenon, 1989:69-76.

12 Duvoisin RC. The evaluation of extrapyramidal disease. In: de Ajuriguerra $J$, Gauthier G, eds. Monoamines noyaux gris centraux et syndrom de Parkinson. Geneva: Georg and Cie, 1971:313-25.

13 Hely MA, Chey T, Wilson A, et al. Reliability of the Columbia scale for assessing signs of Parkinson's Columbia scale for assessing sign
disease. Mov Disord 1993;8:466-72.

14 Canter GJ, De la Torre R, Mier M. A method of evaluating disability in patients with Parkinson's disease. $f$ Nerv Ment Dis 1961:133:143-7.

15 Hoehn MM, Yahr MD. Parkinsonism: onset, progression and mortality. Neurology 1967;17:952-60.

16 Fahn S, Elton RL. Unified Parkinson's disease rating scale. In: Fahn S, Marsden CD, Goldstein M, Calne DB, eds. Recent developments in Parkinson's disease. New Jersey: McMillan, 1987;2:153-63.

17 Prentice R, Marek P. A qualitative discrepancy between censored rank tests. Biometrics 1979;35:861-7.

18 Reid WGJ, Broe GA, Hely MA, et al. The neuropsychology of de novo patients with idiopathic Parkinson's disease: the effects of age of onset. Int $\mathcal{f}$ Neurosci 1989; 48:205-17.

19 Hely MA, Morris JGL, Lawrence S, et al. Retroperitoneal fibrosis, skin and pleuropulmonary changes associated
with bromocriptine therapy [letter]. Aust $N Z \exists \mathrm{Med}$ with bromocript

20 Boshes B. Sinemet and the treatment of Parkinson's disease. Ann Intern Med 1981;94:364-70.

21 Shaw KM, Lees AJ, Stern GM. The impact of treatment with levodopa on Parkinson's disease. $Q \mathcal{F}$ Med 1980 195:283-93.

22 Parkinson's Disease Research Group in the United Kingdom. Comparison of therapeutic effects of levodopa, levodopa and selegiline, and bromocriptine in patients with early, mild Parkinson's disease: three year interim report. $B M \mathcal{F}$ 1993;307:469-72.

23 Riopelle RJ. Bromocriptine and the clinical spectrum of Parkinson's disease. Can f Neurol Sci 1987;14:455-9.

24 Montastruc JL Rascol O, Rascol A A randomised controlled study of bromocriptine versus levodopa in previously untreated Parkinsonian patients: 3 year previously untreated Parkinsonian patients: a 3 year

25 Rollow-up. f Neurol Neurosurg Psychiatry 1989;52:773-5. agonists be given early or late in the treatment of agonists be given early or late in the treatment of

26 Nakanishi T, Mizuno Y, Goto I, et al. A nationwide collaborative study on the long-term effects of bromocriptine in patients with Parkinson's disease. Eur Neurol 1991, 31:3-16.

27 Carlson JH, Bergstran DA, Walters JR. Stimulation of both $D_{1}$ and $D_{2}$ dopamine receptors appears necessary for full expression of postsynaptic effects of dopamin agonists: a neurophysiological study. Brain Res 1987 400:205-18.

28 Beaulieu $M$. Clinical importance of $D_{1}$ and $D_{2}$ receptors. Can f Neurol Sci 1987;14:402-6.

29 Mercuri NB, Calabresi P, Bernardi G. Physiology and pharmacology of dopamine $D_{2}$-receptors: their implications in dopamine-substitute therapy for Parkinson's disease. Neurology 1989;39:1106-8.

30 Barbeau MD, Roy M. Six year results of treatment with levodopa plus benserazide in Parkinson's disease. levodopa plus benserazide

31 Markham CH, Diamond SG. Long-term follow-up of early dopa treatment in Parkinson's disease. Ann Neurol 1986;19:365-72.

32 Hoehn M. Result of chronic levodopa therapy and its modification by bromocriptine in Parkinson's disease. Acta Neurol Scand 1985;71:97-106.

33 Rajput AH, Stern W, Lavery WH. Chronic low-dose levodopa therapy in Parkinson's disease: an argument fo delaying levodopa therapy. Neurology 1984;34:991-6.

34 Caraceni T, Scigliano G, Musicco $M$. The occurrence of motor fluctuations in Parkinsonian patients treated long term with levodopa: Role of early treatment and disease progression. Neurology 1991;41:380-4. 